\title{
Examining the Effectiveness of Public Involvement from the Beginning Stage of Railway Projects to Improve Accessibility in Japan -Based on a Satisfaction Survey on Accessibility Achieved in Three Best Practices from the 1990 s to the 2010 s-
}

\author{
Yoshito DOBASHI ${ }^{\mathrm{a}, 1}$ and Nobuaki OHMORI ${ }^{\mathrm{b}}$ \\ ${ }^{a}$ Visiting Professor, School of Regional Design, Utsunomiya University \\ ${ }^{\mathrm{b}}$ Professor, School of Regional Design, Utsunomiya University
}

\begin{abstract}
In this paper, we examined and confirmed the effectiveness of public involvement in improving accessibility in three selected railway projects. These are the Hankyu-Itami Station project, Fukuoka Nanakuma Subway project, and Sendai Tozai Subway project. As we had already previously analyzed the approaches and processes of the three projects through stakeholder interviews and literature reviews, we next carried out a satisfaction survey to collect passengers' voices, including both persons with and without mobility difficulties. Through the survey, we found that passengers with mobility difficulties benefit more from accessible facilities that have been planned via public involvement. We also found that accessible facilities continue to provide barrier-free and universal design access over time. Judging from our findings, we support the view that public involvement is an effective approach to improving satisfaction in the usability of barrier-free and universal design facilities.
\end{abstract}

Keywords. Public involvement, usability, persons with mobility difficulties, effectiveness, satisfaction, accessibility

\section{Introduction}

From the global aspect, accessibility in public transportation has improved since the Americans with Disabilities Act (ADA) was enacted in the United States in 1990. The concept spread worldwide, calling for the active involvement of local communities and persons with disabilities (hereafter, PWD) [1], in particular. In other countries, the Australian Disability Discrimination Act of 1992 and the U.K. Disability Discrimination Act of 1995 also contain provisions for anti-discrimination based on

${ }^{1}$ Corresponding Author: Urban Planning Lab, Regional Design Department, Utsunomiya University, Bldg. No. 8, 7-1-2 Yoto, Utsunomiya City, Tochigi, Japan. E-mail: dobashi@cc.utsunomiya-u.ac.jp / dobashi@lime.plala.or.jp 
disabilities, and have accelerated the improvement of accessibility. Furthermore, the UN Convention on the Rights of Persons with Disabilities includes mention of participation in the preamble and accessibility in Chapter 9.

In Japan, accessibility in transportation has seen rapid improvement over the last couple of decades owing not only to international trends associated with ADA but also to the implementation of various national and local laws and guidelines, including local government ordinances that promote "welfare towns." Two major national laws for accessible buildings and transportation were merged into the Act on Promotion of Smooth Transportation, etc. of Elderly and Disabled Persons in 2006. In accordance with such merging and revision of laws, national guidelines have also been revised from time to time. For instance, the national barrier-free guideline for public transportation facilities, which was published in 1983, was revised in 1994, 2001, 2007, 2013, 2018, and 2019.

Furthermore, some public transportation facilities were built to standards that were higher those specified in the guidelines. Such best practices were made possible particularly owing to public involvement (hereinafter, PI). However, while there are many books, reports, and articles about these practices, there are hardly any academic papers or practical evaluation reports about them.

As represented by the Policy to Promote Barrier-free and Universal Design (2008), the Japanese government has been promoting accessible environments by using and integrating the concepts of barrier-free and universal design [2]. It is therefore difficult to differentiate accessibility efforts from barrier-free and universal design efforts in Japan. Thus, in this paper, all efforts for making facilities accessible will be defined as both barrier-free and universal design unless otherwise specified.

The purpose of this study is to examine the following issues by collecting evidence through a questionnaire survey on accessibility among persons with mobility difficulties (hereafter, PwMD). The first issue is to prove the effectiveness of PI in railway accessibility projects based on evaluations by PwMDs, including PWDs. The second is to compare three best practices in railway projects in Japan, to identify necessary and effective approaches for improving future accessibility.

\section{Literature Review}

The effectiveness of accessible facilities has been evaluated using a variety of methods, including cross-sector analysis surveys, estimations of equivalent time coefficients, cost-benefit analysis surveys, analyses based on the Analytic Hierarchy Process (AHP), customer satisfaction surveys, and the Contingent Valuation Method (CVM). These methods may be useful and effective in the planning stages, but they have never been used to verify whether pre-assumptions have in fact been correct or effective.

A number of customer satisfaction surveys have been conducted in the past particularly by the Foundation for Promoting Personal Mobility and Ecological Transportation (hereafter, Eco-Mo Foundation), but they lacked enough samples for evaluation and were unable to provide proof of effectiveness. A large-scale, beforeand-after study on accessibility was conducted in Norway [3] in six cities with about 1500 samples, but it reflected only the qualitative views of PWDs.

In sum, it can be said that no previous studies have been conducted on the usability or satisfaction of accessible facilities as evaluated by PwMDs and PWDs, after inauguration of each railway project. 
There are various discussions and papers on the issue of participation, but in this paper, the various types of participatory approaches will be referred to as public involvement, or PI. Studies on PI have been conducted in Japan particularly in terms of basic plans and areas for accessible improvement. However, while detailed surveys have been implemented, they mainly focused on the aspects of coordination and efforts only. None focused on the usability or satisfaction of users as a consequence of the participatory approach.

The Hankyu-Itami Station project was planned before the introduction of universal design in the 2000s in Japan, and is the only project among the three case studies in which ex-post evaluations were conducted [4]. The evaluations were carried out in 1999 and 2003. The overall result showed a roughly 65 to $77 \%$ level of satisfaction with the station's accessibility. However, only a limited number of PwMDs responded to the surveys-approximately 80 in the 1999 survey and 50 in the 2003 survey. Moreover, these evaluations were not statistically analyzed. Many papers and articles about the project have been published, but they basically focus on the participatory activities of the project and not on usability [4] [5].

The history of the Fukuoka Nanakuma Subway project was published as a book [6] and has been referenced in many academic conferences and papers [7]. However, none has focused on the effect of PI on accessibility. The sole survey conducted by the Fukuoka Transport Bureau was on the universal design of Nanakuma Subway in 2012 [8], based on 27 samples whose attributes were not identified.

Studies on the Sendai Tozai Subway project were published in several papers from the technical and engineering aspects, but no academic papers have been published that examined the PI approach or passenger satisfaction with the subway's accessibility. The website of the Sendai City Transportation Bureau simply provides information on the efforts that were made to achieve the facilities and not on the contribution of the local community [9].

Table 1 shows the results of the literature review and stakeholder interviews conducted in each site in our previous study in 2018 [10] [11]. Table 2 shows the unique efforts made in each project in relation to local government guidelines for accessibility. As the required level of accessibility and the year of inauguration differed for each project, the efforts made in each project were compared with the guidelines for each project area at the time the respective station or line was inaugurated.

In this paper, the efforts made in each project are considered to be a result of PI, based on the assumption that if each executing agency, local government, or local transportation bureau had only conformed to the standards of local guidelines, most of the relevant facilities would not have been installed or realized. The facilities were installed in response to strong demands and requests from PWDs and other persons concerned, as shown by items with an asterisk $(*)$ in Table 2 . The unique efforts made per request from residents are marked in bold, and those that went beyond the guidelines are underlined.

The objective of this research is to examine whether the accessibility of public railway transportation can be improved by introducing PI. There has always been a tacit assumption of this thought, but it has never been proven in qualitative or quantitative terms. By proving the effectiveness of PI, PI can be expected to be more widely and deeply introduced to public transportation projects. 
Previous to this paper, Dobashi \& Ohmori $[2 ; 10]$ conducted a qualitative study of the Hankyu-Itami Station project, Fukuoka Nanakuma Subway project, and Sendai Tozai Subway project through literature reviews, site visits, and stakeholder interviews. Thus, in this study, we conducted a large-scale questionnaire survey on the three projects to acquire statistically significant data that would prove the effectiveness of accessible facilities in light of the views of actual passengers and especially PwMDs. We compared differences in satisfaction level between stations and facilities planned with and without PI, and between PwMDs and ordinary passengers.

Other measurement methods such as the time trade-off method, AHP and CVM, do not approach the issue from the subjective viewpoint of the passengers, so we evaluated accessibility through passenger satisfaction levels. The questionnaires were created based on various previous studies which attempted to grasp the satisfaction level of passengers.

Table 1. Outline of PI for accessible facilities in three projects

\begin{tabular}{|c|c|c|c|}
\hline & $\begin{array}{c}\text { Hankyu-Itami Station project } \\
(1996-1998)\end{array}$ & $\begin{array}{c}\text { Fukuoka Nanakuma Subway } \\
\text { project }(1995-2005)\end{array}$ & $\begin{array}{c}\text { Sendai Tozai Subway project } \\
(2003-2015)\end{array}$ \\
\hline 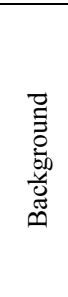 & $\begin{array}{l}\text { In the process of } \\
\text { reconstructing the old } \\
\text { Hankyu-Itami Station which } \\
\text { collapsed in the earthquake, } \\
\text { DPO and others requested that } \\
\text { it be made accessible. } \\
\text { Accessibility of the building } \\
\text { was realized through a } \\
\text { participatory approach. }\end{array}$ & $\begin{array}{l}\text { From the planning stage, the } \\
\text { Fukuoka City Transportation } \\
\text { Bureau involved PwMDs in } \\
\text { discussions and hearings. } \\
\text { Many PwMDs were also } \\
\text { invited to demonstration } \\
\text { experiments. }\end{array}$ & $\begin{array}{l}\text { In } 2010 \text { when the project } \\
\text { entered the construction stage } \\
\text { of facilities, the Sendai City } \\
\text { Transportation Bureau invited } \\
\text { DPOs to discuss how to make } \\
\text { the subway more accessible. } \\
\text { Thereafter, the subway opened } \\
\text { in } 2015 \text {. }\end{array}$ \\
\hline 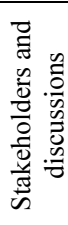 & $\begin{array}{l}\text { A committee was organized } \\
\text { composed of representatives } \\
\text { from three civil societies, a } \\
\text { transportation company, } \\
\text { academia, Itami City and } \\
\text { residents concerned. }\end{array}$ & $\begin{array}{l}\text { Through the Fukuoka City } \\
\text { Committee of Disabled } \\
\text { People's Organizations, the } \\
\text { Fukuoka Transportation } \\
\text { Bureau consulted and } \\
\text { discussed with some } 30 \\
\text { groups and organizations. }\end{array}$ & $\begin{array}{l}\text { The Bureau consulted with the } \\
\text { Sendai City Welfare } \\
\text { Association for the Disabled } \\
\text { and } 14 \text { related groups, and } \\
\text { furthermore invited other } \\
\text { DPOs ( } 8 \text { groups) to join the } \\
\text { discussions. }\end{array}$ \\
\hline
\end{tabular}

(Source: Dobashi \& Ohmori [10], Ohmori \& Dobashi [11])

\section{Method}

We conducted a questionnaire survey on usability in relation to the three projects, targeting local disabled people's organizations (DPO) and monitors of Rakuten Insight Inc., an online market research company. In this paper, we equate the level of satisfaction with each item or the usability of each item as accessibility. Table 3 shows an overview of the questionnaire, and Table 4 the main questions thereof.

We attempted to confirm the effectiveness of accessibility efforts by analyzing the satisfaction level of passengers who answered the questionnaire. The targeted respondents were wheelchair users; PWDs with lower limb disabilities, upper limb disabilities, visual disabilities, hearing disabilities, mental, intellectual, or developmental disabilities, and internal impediments; pregnant mothers and parents with an infant; and sick and injured persons. In this study, we analyzed the responses of wheelchair users, PWDs with visual disabilities, PWDs with lower limb disabilities, and abled-bodied passengers. 
Table 2. Unique efforts made in each project in comparison with guidelines

\begin{tabular}{|c|c|c|c|}
\hline$\overbrace{\underline{\Xi}}^{\mathscr{E}}$ & Hankyu-Itami Station & $\begin{array}{c}\text { Fukuoka Nanakuma } \\
\text { Subway }\end{array}$ & Sendai Tozai Subway \\
\hline & $\begin{array}{ll}\text { 1) } & \text { Easy-to-follow flow lines } \\
\text { 2) } & \text { Larden of Lights) } \\
\text { Large elevators ( } 20 \\
\text { persons }+15 \text { persons)* } \\
\text { 3) } & \text { Escalators (up and } \\
\text { down)* } \\
\text { 4) } & \text { Rooftop parking with } \\
\begin{array}{l}\text { roofed parking spaces for } \\
\text { PWDs* }\end{array} \\
\text { 5) } & \text { Smooth transfer with } \\
\underline{\text { other public }} & \begin{array}{l}\text { transportation means } \\
\text { (bus and taxi)* }\end{array}\end{array}$ & 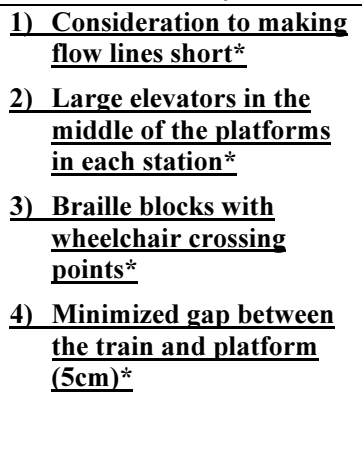 & $\begin{array}{l}\text { 1) Two wheelchair } \\
\frac{\text { accessible routes in all }}{\text { stations* }} \\
\text { 2) Mainly through-type } \\
\begin{array}{l}\text { elevators (13-18 } \\
\text { passenger capacity per } \\
\text { car)* }\end{array} \\
\text { 3) } \begin{array}{l}\text { Installation of braille } \\
\text { blocks in the middle of }\end{array} \\
\text { corridors } \\
\text { 4) Minimized gap between } \\
\begin{array}{l}\text { the train and platform } \\
\text { using rubber (2-3cm)* }\end{array}\end{array}$ \\
\hline & $\begin{array}{l}\text { 6) One wide entrance gate* } \\
\text { 7) Accessible toilets for men } \\
\frac{\text { and women* }}{\text { 8) Grippy floor in the }} \\
\text { station* }\end{array}$ & $\begin{array}{ll}\text { 5) } & \text { Braille blocks leading to } \\
\text { a wide entrance gate and } \\
\text { an automatic gate in the } \\
\text { center* } \\
\text { 6) } \\
\text { Two accessible toilets for } \\
\begin{array}{l}\text { users with left or right } \\
\text { side paralysis in all }\end{array} \\
\text { stations* } \\
\text { 7) } & \text { Straight platforms* } \\
\text { 8) } & \text { Wheelchair space in all } \\
\text { train cars* }\end{array}$ & $\begin{array}{ll}\text { 5) } & \text { All wide entrance gates* } \\
\text { 6) } \text { Braille blocks leading to } \\
\begin{array}{l}\text { an automatic gate in the } \\
\text { center of the entrance } \\
\text { gate* }\end{array} \\
\text { 7) } \text { Two accessible toilets in } \\
\begin{array}{l}\text { and outside all stations } \\
\text { for users with left or } \\
\text { right side paralysis* }\end{array} \\
\text { 8) Straight platforms } \\
\text { 9) Wheelchair space in all } \\
\text { train cars* }\end{array}$ \\
\hline & $\begin{array}{l}\text { 9) } \text { Installation of tactile } \\
\frac{\text { maps with audio }}{\text { guidance }} \\
\text { 10) Installation of voice } \\
\text { guides } \\
\text { 11) Announcement and } \\
\begin{array}{l}\text { visual platform guides } \\
\text { with variable messages }\end{array}\end{array}$ & $\begin{array}{l}\text { 9) } \begin{array}{l}\text { Easy-to-recognize } \\
\text { signage (large reversed } \\
\text { characters, etc.)* }\end{array} \\
\text { 10) Installation of voice } \\
\begin{array}{l}\text { guides with careful } \\
\text { consideration of volume* }\end{array} \\
\text { 11) Installation of signboards } \\
\frac{\text { with careful }}{\text { consideration to height* }} \\
\text { 12) Utilization of lights as a } \\
\frac{\text { signage to navigate }}{\text { passengers to the train }}\end{array}$ & $\begin{array}{l}\frac{10) \text { Installation of a tactile }}{\text { map in front of the }} \\
\frac{\text { entrance gate of subway }}{\text { stations* }} \\
\frac{\text { 11) Voice guides and sound }}{\text { signs* }} \\
\frac{\text { 12) Signage with variable }}{\text { messages* }}\end{array}$ \\
\hline 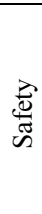 & $\begin{array}{l}\text { 12) Screen to prevent people } \\
\text { from falling from the } \\
\text { platform* } \\
\text { 13) Slope for evacuation } \\
\text { from the platform in case } \\
\text { of emergency" }\end{array}$ & $\begin{array}{l}\text { 13) Installation of platform } \\
\text { doors in all stations* }\end{array}$ & $\frac{\text { 13) Installation of platform }}{\text { doors in all stations }}$ \\
\hline
\end{tabular}


The responses of PwMDs and able-bodied passengers were compared to examine the effectiveness of accessible facilities in terms of the difference in satisfaction level between those who are affected by or benefit from accessible facilities and those who are not affected by or do not benefit from accessible facilities. The difference in satisfaction level was compared using the chi-square test to examine whether it is statistically significant for all stations. We also compared the respondents' level of satisfaction with accessible stations and with stations they specified for comparison (stations not planned with PI; herein referred to as contrast stations).

Comparisons were made with regard to the six items of overall station, movement, facility, information, staff service, and safety, in reference to previous studies done by Eco-Mo Foundation [5] and others. These previous studies have all been academically and statistically approved as official reports.

The contrast stations are stations that the respondents said they use most frequently besides the three accessible lines, as shown in Table 5 . They are mostly stations along lines operated by the same operators as the accessible lines. Particularly in the case of Sendai Tozai Subway, 66\% of the contrast stations were stations of the Sendai Namboku Subway. Three of the stations were said to be planned with PI, but according to the stakeholder interview, PI was introduced only nominally. Therefore, it could be said that all contrast stations were planned through a non-participatory approach.

Table 3. Overview of the questionnaire survey (distribution and responses)

\begin{tabular}{|c|c|c|c|c|}
\hline & $\begin{array}{l}\text { Hankyu-Itami } \\
\text { Station }\end{array}$ & $\begin{array}{c}\text { Fukuoka } \\
\text { Nanakuma } \\
\text { Subway }\end{array}$ & $\begin{array}{l}\text { Sendai Tozai } \\
\text { Subway }\end{array}$ & Total \\
\hline Methods & \multicolumn{3}{|c|}{ Paper, Web, speech-to-text, telephone } & - \\
\hline Period & \multicolumn{3}{|c|}{ October 25,2018 to January 15,2019} & - \\
\hline Distribution through DPOs & 650 & 430 & 190 & 1270 \\
\hline $\begin{array}{l}\text { Distribution to monitors of } \\
\text { Rakuten Insight }\end{array}$ & 200 & 200 & 200 & 600 \\
\hline Total distribution & 850 & 630 & 390 & 1870 \\
\hline Responses by PwMDs & 205 & 172 & 106 & 483 \\
\hline $\begin{array}{c}\text { Responses by able-bodied } \\
\text { passengers }\end{array}$ & 166 & 169 & 164 & 499 \\
\hline Total responses & 371 & 341 & 270 & 982 \\
\hline
\end{tabular}

Table 4. Main questions of the questionnaire

\begin{tabular}{|c|c|}
\hline 1. Attributes & Sex, age, occupation, types of mobility difficulty, etc. \\
\hline 2. Train usage & Main methods of travel, frequency of using railways, etc. \\
\hline \multirow{2}{*}{$\begin{array}{l}\text { 3. Personal } \\
\text { satisfaction } \\
\text { with the } \\
\text { usability of the } \\
\text { station or } \\
\text { railway }\end{array}$} & $\begin{array}{l}\text { Satisfaction with the usability of the target station or railway } \\
\text { Satisfaction with the usability of the station or railway used most frequently other than } \\
\text { the abovementioned station or railway }\end{array}$ \\
\hline & $\begin{array}{l}\text { (Questions): Please answer your level of satisfaction with the following items. } \\
\text { (Items) 1. Overall station, 2. Movement, 3. Facilities, } 4 \text {. Information, 5. Staff service, } \\
\text { 6. Safety (1. Overall station and 5. Staff service were added to the items in Table 2) } \\
\text { (Level of satisfaction) } \\
\text { 1. Very satisfied, 2. Satisfied, 3. Neither/nor, 4. Not satisfied, 5. Very unsatisfied }\end{array}$ \\
\hline 4. Other & $\begin{array}{l}\text { Participation at the planning stage } \\
\text { Sense of familiarity with the stations and railways, etc. }\end{array}$ \\
\hline
\end{tabular}


Table 5. Contrast stations specified by respondents

\begin{tabular}{|c|c|c|c|c|c|}
\hline & $\begin{array}{l}\text { Railway } \\
\text { company }\end{array}$ & $\begin{array}{c}\text { Number of } \\
\text { contrast } \\
\text { stations }\end{array}$ & $\begin{array}{l}\text { Specified } \\
\text { facilities } \\
\text { required to be } \\
\text { accessible }\end{array}$ & $\begin{array}{l}\text { Introduction } \\
\text { of PI }\end{array}$ & $\begin{array}{l}\text { Number of } \\
\text { respondents } \\
(\%)\end{array}$ \\
\hline \multirow{3}{*}{$\begin{array}{c}\text { Passengers of } \\
\text { Hankyu- } \\
\text { Itami Station }\end{array}$} & $\begin{array}{c}\text { Japan Railway } \\
\text { (JR) }\end{array}$ & 16 & 2 & 2 & $113(62 \%)$ \\
\hline & Hankyu & 18 & 8 & 1 & $58(32 \%)$ \\
\hline & Others & 9 & 4 & 0 & $12(7 \%)$ \\
\hline Total & - & 43 & 14 & 3 & 183 \\
\hline \multirow{4}{*}{$\begin{array}{l}\text { Passengers of } \\
\text { Fukuoka } \\
\text { Nanakuma } \\
\text { Subway }\end{array}$} & $\begin{array}{l}\text { Fukuoka } \\
\text { Kuko } \\
\text { Subway }\end{array}$ & 12 & 11 & 0 & $68(40 \%)$ \\
\hline & JR & 21 & 10 & 0 & $46(27 \%)$ \\
\hline & Nishitetsu & 21 & 7 & 0 & $40(24 \%)$ \\
\hline & Others & 8 & 7 & 0 & $14(8 \%)$ \\
\hline Total & - & 59 & 35 & 0 & 168 \\
\hline \multirow{3}{*}{$\begin{array}{l}\text { Passengers of } \\
\text { Sendai Tozai } \\
\text { Subway }\end{array}$} & $\begin{array}{c}\text { Sendai } \\
\text { Namboku } \\
\text { Subway }\end{array}$ & 16 & 14 & $\mathbf{0}$ & $67(66 \%)$ \\
\hline & JR & 13 & 4 & 0 & $25(25 \%)$ \\
\hline & Others & 4 & 0 & 0 & $9(9 \%)$ \\
\hline Total & - & 37 & 18 & 0 & 101 \\
\hline
\end{tabular}

(*) The same railway companies are expressed in bold and shaded.

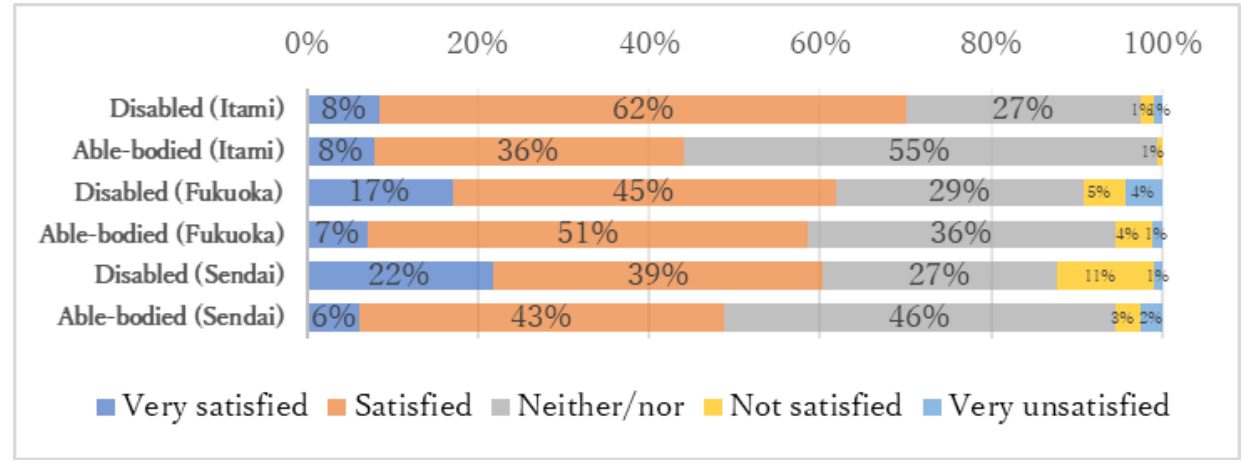

\section{Figure 1. Level of satisfaction with accessibility in the three projects}

(SPSS: chi-square test between PwMDs (as "disabled") and able-bodied passengers: Itami $\mathrm{p}=0.00$, Fukuoka $\mathrm{p}=0.02$, Sendai $\mathrm{p}=0.00$ )

\section{Results}

\subsection{Analysis of the level of satisfaction with the usability of facilities and stations}

Figure 1 shows an overview of the level of satisfaction with accessibility among PwMDs and able-bodied passengers. These are the answers to the level of satisfaction regarding overall station. In this figure, satisfaction levels are divided into five levels: very satisfied, satisfied, neither/nor, not satisfied, very unsatisfied. We used this subjective scale as it is difficult to compare railway stations and lines in different areas due to differences in ordinances and guidelines. 
Although we used the five-level scale, we did not apply the Likert scale, as we aimed to analyze whether the respondents are content with railway stations and facilities built with PI. Furthermore, the five-level scale was used in Figure 1 only; later, very satisfied and satisfied were categorized as "well satisfied," and neither/nor, not satisfied and very unsatisfied were categorized as "not well satisfied." In all figures and tables, chi-square tests were applied.

The main objective of this study is to prove that railway projects planned with PI are effectively accessible. In this regard, as the results for overall station are statistically significant in all three railway projects with a p-value from 0.00 to 0.02 as shown in Figure 1, we can say that railway stations planned with PI are more accessible to PwMDs than to able-bodied passengers.

In addition to the difference in satisfaction levels between PwMDs and able-bodied passengers, we also examined the difference between the respondents' level of satisfaction with railway stations and lines which were planned with PI and those planned without PI. As a result, we found that stations planned with PI are more accessible than stations planned without PI, as shown in Table 6. This is the main finding of this study. Previous studies were unable to prove the significance of this observation in statistical terms due to a lack of enough respondents, or did not attempt to prove it statistically in the first place. As shown in Figure 1, more than $60 \%$ of all respondents answered "well satisfied," thereby indicating the statistical significance of the finding. Such statistical proof was able to be obtained owing to the dedicated cooperation of local DPOs in collecting sufficient samples.

Table 6 shows the result of the questionnaire regarding the three railway projects. As described above, respondents were asked to evaluate the six items mentioned above in "3. Method," and their levels of satisfaction were regrouped into two categories, "well satisfied" and "not well satisfied." The chi-square test was applied to all responses showing the satisfaction levels of PwMDs and able-bodied passengers regarding the three projects, and passengers' level of satisfaction regarding stations planned with and without PI.

Judging by the responses of all PwMDs, it can be said that PwMDs are more satisfied with railway projects planned with PI. A statistically significant difference was seen for 11 of the 18 items for evaluation of the three projects combined, and particularly for facility and safety (Line C).

There are ordinances that stipulate the installation of "specific accessible passenger facilities" in contrast railway stations, but while these stations are supposedly accessible, satisfaction levels were higher for stations planned with PI than for stations with specific accessible passenger facilities, as shown in Table 6.

\subsection{Further analysis on the level of satisfaction with usability between the three projects and contrast station/lines in terms of the six items for evaluation}

In this section, we compare and analyze the results of the six items for evaluation in each of the three projects and contrast station/lines, as shown in Table 6.

\subsubsection{Hankyu-Itami Station}

Among all PwMDs, their level of satisfaction with the usability of Hankyu-Itami Station was higher compared to the contrast stations and statistically significant in most cases. As Hankyu-Itami Station was the first station in Japan to be planned with PI, stakeholders made full efforts to build a thoroughly accessible station. 
Table 6. Level of satisfaction with usability in the three projects

(\% of "well satisfied" responses)

\begin{tabular}{|c|c|c|c|c|c|c|c|c|c|c|}
\hline \multirow{2}{*}{ 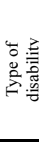 } & \multirow[t]{2}{*}{ Items } & \multicolumn{3}{|c|}{ Hankyu-Itami Station } & \multicolumn{3}{|c|}{$\begin{array}{c}\text { Fukuoka Nanakuma } \\
\text { Subway }\end{array}$} & \multicolumn{3}{|c|}{ Sendai Tozai Subway } \\
\hline & & $\begin{array}{c}\text { Surveyed } \\
\text { station } \\
(\%)(\mathrm{A}) \\
\end{array}$ & $\begin{array}{l}\text { Contrast } \\
\text { station } \\
(\%)(B) \\
\end{array}$ & $\begin{array}{l}\text { Difference } \\
(\%)(\mathrm{C})\end{array}$ & $\begin{array}{c}\text { Surveyed } \\
\text { station } \\
(\%)(\mathrm{A}) \\
\end{array}$ & $\begin{array}{l}\text { Contrast } \\
\text { station } \\
(\%)(B) \\
\end{array}$ & $\begin{array}{l}\text { Difference } \\
(\%)(\mathrm{C})\end{array}$ & $\begin{array}{l}\text { Surveyed } \\
\text { station } \\
(\%)(\mathrm{A})\end{array}$ & $\begin{array}{l}\text { Contrast } \\
\text { station } \\
(\%)(B) \\
\end{array}$ & $\begin{array}{c}\text { Difference } \\
(\%)(\mathrm{C})\end{array}$ \\
\hline \multirow{6}{*}{ 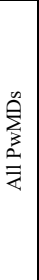 } & $\begin{array}{l}\text { Overall } \\
\text { station }\end{array}$ & $70.1 * *$ & 51.1 & $19.0 * *$ & 61.8 & 57.3 & 4.5 & 60.4 & 55.8 & 4.6 \\
\hline & Movement & $68.2 * *$ & 44.7 & $23.5^{* *}$ & 63.6 & 44.2 & $19.4 * *$ & $62.5 * *$ & $48.9 *$ & 13.6 \\
\hline & Facility & $55.5^{*}$ & 37.8 & $17.7 * *$ & 66.1 & 43.9 & $22.2 * *$ & $69.2 * *$ & $53.2 *$ & $16.0^{*}$ \\
\hline & Information & 49.8 & 37.3 & $12.5^{*}$ & 60.8 & 39.9 & $20.9 * *$ & $54.3 *$ & 47.3 & 7.0 \\
\hline & Staff service & $59.4 * *$ & 49.7 & 9.7 & 58.0 & 55.6 & 2.4 & $59.0 *$ & $61.1 * *$ & -2.1 \\
\hline & Safety & $50.3 *$ & 29.7 & $20.6^{* *}$ & 81.0* & 43.6 & $37.4 * *$ & $79.6^{* *}$ & $62.5 * *$ & $17.1 * *$ \\
\hline \multicolumn{2}{|c|}{ Respondents } & \multicolumn{3}{|c|}{$\mathrm{n}=205$} & \multicolumn{3}{|c|}{$\mathrm{n}=172$} & \multicolumn{3}{|c|}{$\mathrm{n}=106$} \\
\hline \multirow{6}{*}{ 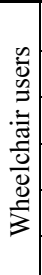 } & $\begin{array}{l}\text { Overall } \\
\text { station }\end{array}$ & $89.3^{* *}$ & 46.2 & $43.1 * *$ & $82.9^{* *}$ & 69.0 & 13.9 & 69.2 & 40.0 & $29.2^{*}$ \\
\hline & Movement & $82.1 * *$ & 48.1 & $34.0 * *$ & 78.0 & 46.2 & $31.8^{* *}$ & $68.0 *$ & 37.5 & $30.5^{*}$ \\
\hline & Facility & 51.7 & 37.0 & 14.7 & $85.0 * *$ & 43.9 & $41.1 * *$ & 65.4 & 37.5 & $27.9^{*}$ \\
\hline & Information & 46.4 & 29.6 & 16.8 & $78.0 *$ & 39.0 & 39.0** & 53.8 & 29.2 & 24.6 \\
\hline & Staff service & $71.4 * *$ & 55.6 & 15.8 & $73.2 * *$ & $68.4 * *$ & 4.8 & $69.2 *$ & $68.0 * *$ & 1.2 \\
\hline & Safety & 58.6 & 29.6 & $29.0 *$ & $87.8 *$ & 39.0 & $48.8^{* *}$ & $80.8 *$ & 56.0 & 24.8 \\
\hline \multicolumn{2}{|c|}{ Respondents } & \multicolumn{3}{|c|}{$n=29$} & \multicolumn{3}{|c|}{$\mathrm{n}=44$} & \multicolumn{3}{|c|}{$n=26$} \\
\hline \multirow{6}{*}{ 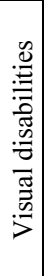 } & $\begin{array}{l}\text { Overall } \\
\text { station }\end{array}$ & $65.9 \%$ & 35.1 & 30.8** & 48.1 & 50.0 & -1.9 & 50.0 & 52.6 & -2.6 \\
\hline & Movement & 62.5 & 37.8 & $24.7^{*}$ & 55.6 & 38.5 & 17.1 & 60.0 & $60.0 *$ & 0.0 \\
\hline & Facility & 48.8 & $21.6^{*}$ & $27.2 *$ & 59.3 & 42.3 & 17.0 & 65.0 & $60.0 *$ & 5.0 \\
\hline & Information & 46.3 & 29.7 & 16.6 & 44.4 & 34.6 & 9.8 & 30.0 & 47.4 & -17.4 \\
\hline & Staff service & $63.4^{* *}$ & 45.9 & 17.5 & 55.6 & 52.0 & 3.6 & 50.0 & 50.0 & 0.0 \\
\hline & Safety & 45.0 & 18.9 & $26.1 *$ & 66.7 & 38.5 & $28.2 *$ & $85.0 \%$ & 55.0 & 30.0* \\
\hline \multicolumn{2}{|c|}{ Respondents } & \multicolumn{3}{|c|}{$\mathrm{n}=41$} & \multicolumn{3}{|c|}{$\mathrm{n}=29$} & \multicolumn{3}{|c|}{$\mathrm{n}=20$} \\
\hline \multirow{6}{*}{ 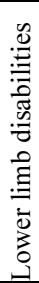 } & $\begin{array}{l}\text { Overall } \\
\text { station }\end{array}$ & $76.2^{* *}$ & 60.0 & 16.2 & 54.5 & 66.0 & -11.5 & 56.7 & 57.1 & -0.4 \\
\hline & Movement & $70.3^{* *}$ & 50.0 & $20.3^{*}$ & 60.0 & $58.0 * *$ & 2.0 & 62.1 & $63.0 * *$ & -0.9 \\
\hline & Facility & $59.4 *$ & 42.6 & 16.8 & 57.1 & 55.1 & 2.0 & 67.9 & $63.0^{*}$ & 4.9 \\
\hline & Information & 48.4 & 41.4 & 7.0 & 55.4 & 49.0 & 6.4 & $62.1 *$ & 57.1 & 5.0 \\
\hline & Staff service & $60.0 * *$ & 48.2 & 11.8 & 62.3 & 59.2 & 3.1 & 62.1 & $59.3 * *$ & 2.8 \\
\hline & Safety & 47.6 & 31.0 & 16.6 & $88.7^{* * *}$ & 56.0 & $32.7 * *$ & 75.9 & $64.3 * *$ & 11.6 \\
\hline \multicolumn{2}{|c|}{ Respondents } & \multicolumn{3}{|c|}{$n=66$} & \multicolumn{3}{|c|}{$\mathrm{n}=57$} & \multicolumn{3}{|c|}{$\mathrm{n}=30$} \\
\hline 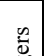 & $\begin{array}{l}\begin{array}{l}\text { Overall } \\
\text { station }\end{array} \\
\end{array}$ & 44.0 & 50.3 & -6.3 & 58.6 & 52.8 & 5.8 & 48.8 & 51.5 & -2.7 \\
\hline 音 & Movement & 51.2 & 44.1 & 7.1 & 62.1 & 36.6 & $25.5 * *$ & 44.5 & 33.0 & 11.5 \\
\hline $\begin{array}{l}0 \\
0 \\
\tilde{a} \\
2\end{array}$ & Facility & 43.4 & 44.8 & -1.4 & 61.5 & 46.3 & $15.2 * *$ & 51.2 & 35.9 & $15.3^{*}$ \\
\hline 总 & Information & 42.2 & 42.7 & -0.5 & 58.0 & 49.6 & 8.4 & 38.4 & 39.8 & -1.4 \\
\hline 吕 & Staff service & 36.7 & 39.2 & -2.5 & 47.3 & 43.9 & 3.4 & 43.3 & 32.0 & 11.3 \\
\hline $\mathbb{Z}$ & Safety & 39.8 & 29.4 & 10.4 & 71.0 & 41.5 & $29.5^{* *}$ & 60.4 & 36.9 & $23.5 * *$ \\
\hline Res & pondents & & $\mathrm{n}=166$ & & & $\mathrm{n}=169$ & & & $\mathrm{n}=164$ & \\
\hline & $\begin{array}{l}\text { are test: } \mathrm{p} \\
\text { ures are ite }\end{array}$ & . & he level of & level of & . & able-b & ed sta & $\mathrm{dec}$ & $\begin{array}{l}\text { survey } \\
\text { o contr } \\
\text { tions }\end{array}$ & $\begin{array}{l}\text { ions } \\
\text { tions }\end{array}$ \\
\hline
\end{tabular}


There was a statistically significant difference between PwMDs and able-bodied passengers in five of the six items (Line A). There was also a statistically significant difference between the said station and contrast stations in five of the six items (Line C), and statistically significant differences among passengers with different disabilities. On the other hand, there was no significant difference between the said station and contrast stations among able-bodied passengers.

\subsubsection{Fukuoka Nanakuma Subway}

Among all PwMDs and wheelchair users, satisfaction levels were higher for all items of the surveyed stations compared to the contrast stations, but not all were statistically significant. Statistical significance was seen in the items of movement, facility, information and safety between Nanakuma Subway stations and contrast stations (Line C). Among PWDs with visual disabilities and lower limb disabilities, satisfaction levels were higher for five of the six items, but only safety was statistically significant. An interesting finding with regard to Nanakuma Subway was that among able-bodied passengers, their satisfaction level was statistically significant for the three items of movement, facility and safety. This could be interpreted as a result of the effort to introduce universal design to Nanakuma Subway to also benefit ordinary passengers.

In a comparison with able-bodied passengers (Line A), satisfaction levels among wheelchair users were statistically significant for the five items of overall station, facility, information, staff service and safety. Furthermore, the level of satisfaction with safety was statistically significant among all PwMDs and PWDs with lower limb disabilities.

\subsubsection{Sendai Tozai Subway}

Among most PwMDs and wheelchair users, their level of satisfaction with regard to Sendai Tozai Subway was higher than the contrast stations for most items, except for staff service among PwMDs, data-wise. Statistical significance was seen in only some items, such as facility and safety among all PwMDs, and overall station, movement, and facilities among wheelchair users (Line C). Surprisingly, among visually disabled people, their level of satisfaction with some items was equal to or higher for contrast stations, although the data indicated no statistical significance. The only statistically significant item among visually disabled people was safety. Among able-bodied passengers, their level of satisfaction for facility and safety was statistically significant compared to the contrast stations. As shown in Table 5, up to two-thirds of the contrast stations for Sendai Tozai Subway were stations along Sendai Namboku Subway, and most of the facilities that were introduced to Sendai Tozai Subway have also been introduced to Sendai Namboku Subway, such as platform doors, sound signage, and all wide entrance gates.

Compared to able-bodied passengers (Line A), the level of satisfaction among all PwMDs, wheelchair users, visually disabled people and PWDs with lower limb disabilities, was the same for some items and different for other items. This indicated a difference in tendencies.

\subsection{Analysis of the comparison between the three accessible station/lines and contrast station/lines}

When comparing the accessible stations of the three projects with contrast stations, statistical significance was seen in the level of satisfaction for facility and safety among 
all PwMDs, for movement among wheelchair users, and for safety among visually disabled people. Also, when comparing PwMDs and able-bodied passengers, statistical significance was seen in the level of satisfaction for safety among all PwMDs and staff service among wheelchair users.

Notably, in Table 6, the difference in the level of satisfaction between HankyuItami Station, which was built 20 years ago, and contrast stations was much larger than the difference between the other two lines and their contrast stations. For instance, the difference in the level of satisfaction for overall station between Hankyu-Itami Station and contrast stations was 19\% among all PwMDs but $4.6 \%$ for Sendai Tozai Subway, the latest subway in Japan, and $4.5 \%$ for Fukuoka Nanakuma Subway. The reason why satisfaction level was higher for the older subway than the latest subway was due to the contrast stations. As shown in Table 5, 67\% of the contrast stations for Sendai Tozai Subway were stations along Sendai Namboku Subway, operated by the same transportation company. In the case of Hankyu-Itami Station, only 30\% of the contrast stations were operated by the same transportation company, while in the case of Fukuoka Nanakuma Subway, $42 \%$ of the contrast stations were operated by the same Fukuoka Transportation Bureau.

Through interviews with the operating bodies, we confirmed their efforts to apply new measures that have been introduced to their new stations and lines to other stations and lines as much as possible. In fact, when we interviewed a visual DPO in Sendai, the chairperson noted that the accessibility levels of Sendai Tozai Subway and Sendai Namboku Subway were almost the same as of 2019.

When taking the above situation into consideration in comparing the difference in satisfaction to prove the effectiveness of accessibility, we can see that the difference between accessible stations and contrast stations depends on the degree of accessibility relative to the contrast stations rather than the absolute accessibility of the accessible stations.

\subsection{Differences in the level of satisfaction regarding passenger usability in the three projects among PWDs with different disabilities}

\subsubsection{All persons with mobility difficulties}

From Chart 1 and Table 6, we found that the level of satisfaction regarding accessibility is higher among PwMDs than able-bodied passengers. Especially with respect to facility and safety, the satisfaction level among PwMDs was statistically significant and higher than able-bodied passengers in all three projects (Table 6, Line C).

\subsubsection{Wheelchair users}

Considering the results of the survey, wheelchair users benefit the most from accessibility efforts. Table 7 clearly shows that barrier-free/accessibility is the main reason why wheelchair users choose the station they use. This is based on a statistically significant comparison with able-bodied passengers.

Table 6 shows that among people with different types of disabilities, wheelchair users displayed a higher level of satisfaction with the three projects compared to people with other types of disabilities. Wheelchair users of Hankyu-Itami Station showed a statistically significant level of satisfaction for the three items of overall station, movement and staff service. Similarly, in comparison with contrast stations, they 
showed a statistically significant level of satisfaction for the three items of overall station, movement and safety.

With regard to wheelchair passengers of the other two lines, many items were statistically significant in comparison with able-bodied passengers and with contrast stations. On the whole, wheelchair users showed a higher and statistically significant level of satisfaction than people with other types of disabilities.

Table 7. Reasons why wheelchair users choose the stations/lines they use

\begin{tabular}{|l|c|c|c|c|c|c|}
\hline & $\begin{array}{l}\text { 1. Easy } \\
\text { access to } \\
\text { station }\end{array}$ & $\begin{array}{l}2 . \text { Quick to } \\
\text { reach } \\
\text { destination }\end{array}$ & $\begin{array}{l}3 \text {. Little up } \\
\text { and down }\end{array}$ & 4. Fare & $\begin{array}{l}5 . \text { Barrier } \\
\text {-free access }\end{array}$ & $\begin{array}{c}\text { Passengers } \\
\text { (n) }\end{array}$ \\
\hline $\begin{array}{l}\text { Itami } \\
\text { (wheelchair) }\end{array}$ & $55 \% * *$ & $45 \%$ & $3 \%$ & $21 \%$ & $34 \% * *$ & 29 \\
\hline $\begin{array}{l}\text { Itami } \\
\text { (able-bodied) }\end{array}$ & $25 \%$ & $49 \%$ & $11 \%$ & $10 \%$ & $2 \%$ & 166 \\
\hline $\begin{array}{l}\text { Fukuoka } \\
\text { (wheelchair) }\end{array}$ & $30 \%$ & $43 \% *$ & $23 \%$ & $7 \%$ & $64 \% * *$ & 44 \\
\hline $\begin{array}{l}\text { Fukuoka } \\
\text { (able-bodied) }\end{array}$ & $28 \%$ & $60 \%$ & $19 \%$ & $7 \%$ & $3 \%$ & 169 \\
\hline $\begin{array}{l}\text { Sendai } \\
\text { (wheelchair) }\end{array}$ & $19 \%$ & $54 \%$ & $31 \% *$ & $12 \%$ & $54 \% * *$ & 26 \\
\hline $\begin{array}{l}\text { Sendai } \\
\text { (able-bodied) }\end{array}$ & $32 \%$ & $54 \%$ & $13 \%$ & $5 \%$ & $1 \%$ & 164 \\
\hline
\end{tabular}

Chi-square test between the answers of wheelchair users and able-bodied passengers

$$
* *=1 \% \text { level, } *=5 \% \text { level }
$$

\subsubsection{Visually disabled people}

In all three projects, many facilities have been installed to support visually disabled people in their outings. Various efforts have also been made to accommodate their needs. However, as shown in Table 6 , the satisfaction level of visually disabled people was lower than people with other types of disabilities. The difference in their level of satisfaction between Hankyu-Itami Station and contrast stations was two times higher than for Fukuoka Nanakuma Subway and Sendai Tozai Subway.

In the case of Fukuoka Nanakuma Subway, a statistically significant difference was seen only for safety between its stations and contrast stations. In the case of Sendai Tozai Subway as well, a statistically significant difference was seen only for safety between its stations and contrast stations. The reason why the level of satisfaction for safety was higher can be assumed to be related to the installation of platform doors in all stations.

As people's disabilities vary widely from person to person, the sense of familiarity with the stations and facilities makes a difference in the level of satisfaction regarding usability among visually disabled people. Even the latest facilities planned with careful PI is not sufficient to satisfy the majority of PwMDs. Previous studies such as by Montarzino et al [12] and Higashiyama [13] have found that differences in passengers' level of satisfaction regarding accessibility are related to their sense of familiarity. In the open answer section of the survey, some respondents commented that "the usability of Sendai Tozai Subway is not unique or special to me, as I am familiar with Namboku Line." Further detailed studies need to be conducted on the level of satisfaction regarding usability among visually disabled people.

\subsubsection{PWDs with lower limb disabilities}

The difference in the level of satisfaction with regard to overall station, movement and staff service of Hankyu-Itami Station between PWDs with lower limb disabilities and 
able-bodied passengers showed the same statistical significance as the difference for the same items among wheelchair users. However, with Fukuoka Nanakuma Subway, the difference for the same items was statistically significant only for safety. In the case of Sendai Tozai Subway, the difference for the same items was statistically significant only for information.

It is difficult to summarize the tendencies of PWDs with lower limb disabilities, but it has been found that people with different types of disabilities have different levels of satisfaction regarding accessible facilities and items.

\subsubsection{Able-bodied passengers}

In the case of Hankyu-Itami Station, satisfaction levels among able-bodied passengers were lower than the four categories of disabled passengers. Furthermore, in several items, satisfaction levels were higher for contrast stations than the said station, but with no statistically significant difference.

In the case of Fukuoka Nanakuma Subway, there was a statistically significant difference regarding the three items of movement, facility and safety between its stations and contrast stations.

For Sendai Tozai Subway, there was a statistically significant difference regarding facility and safety between its stations and contrast stations.

The reason why there were so many statistically significant differences in satisfaction levels between the said stations and contrast stations may be because Fukuoka Nanakuma Subway is widely known as a subway planned with universal design as its basic concept, and some of Sendai Tozai Subway's components, including the train cars and toilets, also incorporate universal design. As a result, not only PwMDs but also able-bodied passengers benefit from the universal design facilities. In other words, all passengers benefit from them.

From the above analysis, it can be said that the four categories of PWDs benefit from stations planned with PI. Our assumption was therefore generally correct.

\section{Conclusion}

\subsection{Accessibility of railway projects planned with PI}

\subsubsection{Accessibility of stations and lines planned with PI}

Through the three cases examined in this study, we were able to show from the results of a questionnaire survey that railway passengers have a higher level of satisfaction with railway projects planned with PI than those planned without PI. It is difficult to clearly differentiate whether PI is the reason for the high level of satisfaction, but we were able to use a subjective questionnaire to quantitatively show that satisfaction in usability is much higher for projects planned with PI than for those planned without PI. This is something that previous studies have not revealed in statistical terms. The main finding of this study is that PI is effective for making projects accessible, as assumed.

\subsubsection{Different levels of satisfaction due to different contrast stations}

Hankyu-Itami Station, the oldest railway project, was expected to show the lowest level of satisfaction. However, the result of the survey was the contrary. For instance, there was a statistically significant difference for overall station among all four categories of disabled passengers and able-bodied passengers. Thorough, in-depth discussions and 
efforts to provide accessibility have ensured long-life sustainable accessibility of Hankyu-Itami Station.

This may apply to both Fukuoka Nanakuma Subway and Sendai Tozai Subway as well, as they also involved thorough and in-depth discussions and efforts. However, their efforts were not closely examined in this study, because Fukuoka Nanakuma Subway aimed to be a universal design railway, and able-bodied passengers showed a higher level of satisfaction than other projects. In the case of Sendai Tozai Subway, the contrast stations and lines were of Sendai Namboku Subway, to which the Sendai Transportation Bureau applied the same efforts and measures they used for the Tozai Subway.

\subsection{Other findings from a comparison of the study results of the three projects}

\subsubsection{Satisfaction of usability among people with different disabilities}

In this study, we found that PwMDs were more satisfied with railway projects planned with PI than those planned without PI. Among people with different types of disabilities, wheelchair users tended to show a higher level of satisfaction than ablebodied passengers. With regard to visually disabled passengers, their evaluation of usability needs to be considered not only from the physical aspects of facilities but also other elements such as familiarity.

\subsubsection{Unique aspects of accessibility in the three projects}

Although Hankyu-Itami Station was planned almost twenty years ago, its accessibility is still valid and satisfies all categories of disabled passengers. The accessibility of Fukuoka Nanakuma Subway is considered highly satisfactory by wheelchair users and able-bodied passengers, owing to the universal design approach. Satisfaction in the usability of Sendai Tozai Subway was high among all PwMDs, with many items showing almost the same level of satisfaction with Sendai Namboku Line owing to the operator's efforts to apply the accessible facilities of the new Tozai Line to the old Namboku Line. The results of the survey indicate that PwMDs care about the safety of railway station facilities.

\subsubsection{Universal design aspects}

Most PwMDs were satisfied with Hankyu-Itami Station, as it aimed to be an accessible facility. However, the result for Nanakuma Line was unique, since able-bodied passengers were also satisfied with the accessible efforts that aimed for universal design. The Sendai Tozai Subway showed different aspects in providing some facilities as universal design facilities and others as accessible facilities. The accessible efforts ultimately satisfied the large majority of passengers. As defined in the beginning, all accessible efforts are synonymous with barrier-free and universal design efforts, so it can be said from the positive results of this study that PI works effectively for universal design.

\subsection{Issues to be addressed}

In this study, we conducted a thorough survey of three projects only. Therefore, we need to expand the study to other projects to acquire more evidence. We might also need to find a more appropriate index for a comparison of accessibility with different projects. Furthermore, as the level of satisfaction of usability among visually disabled 
people was not as high as expected, this should be a challenge for the future. Lastly, it should be meaningful to discuss what methods and types of participation are effective for creating more accessible environments.

\section{ACKNOWLEDGMENTS}

This study was supported by a grant offered by the Japan Institute of Country-ology and Engineering (JICE) in FY2018 (No. 17011).

\section{AUTHOR CONTRIBUTIONS}

The authors confirm the following contributions to this paper: study conception and design by Dobashi, Ohmori; data collection by Dobashi; analysis and interpretation of results by Dobashi, Ohmori; draft manuscript preparation by Dobashi. All authors have reviewed the results and approved the final version of the manuscript.

\section{References}

[1] U.S. Department of Transportation, Public Involvement Techniques, https://www.planning.dot.gov/PublicInvolvement/pi_documents/1a-b.asp, August 5, 2018.

[2] Y. Dobashi and N. Ohmori, Re-Examining the Creativity of Universal Design Initiatives in Public Spaces in Japan, Studies in health technology and informatics 256 (2018), 279-289.

[3] J. Aarhaug and B. Elvebakk, The impact of Universally accessible public transport-a before and after study, Transport Policy 44 (2015), 143-150.

[4] ECOMO Foundation ed., Aiming for an extremely barrier-free railway station; the process of rehabilitation of Hankyu-Itami station from the Great Hanshin Awaji earthquake, Taisei-shuppan, 2001. (in Japanese)

[5] ECOMO Foundation, Evaluation report on Hankyu Itami station rehabilitation project, ECOMO Foundation, 2003. (in Japanese)

[6] JV group of Fukuoka subway no.3, A Universal Design for Public Transportation: Fukuoka City Subway Nanakuma Line Total Design--A 10-Year History, Sendenkaigi, 2005. (in Japanese)

[7] T. Sadamura, Working to be a subway that easy for everyone to use The "universal design" of the Fukuoka City Subway NANAKUMA Line, in: The 2nd International Conference for Universal Design in Kyoto 2006, Internal Association for Universal Design (IAUD), 2006.

[8] C. Komaki, Satisfaction of Universal Design by the Passengers of Fukuoka Subway: Research at Hashimoto Station as a Joint-Project with International Association for Universal Design Conference 2012, Fukuoka Transporation Bureau, 2012. (in Japanese)

[9] Sendai City Transportation Bureau, Activities towards Safety and Relief, Sendai City Transportation Bureau, https://www.kotsu.city.sendai.jp/kigyou/safety/index.html, April 21, 2019. (in Japanese)

[10] Y. Dobashi and N. Ohmori, Progress of Accessibility in Transportation in Japan Over the Last Three Decades: An Observation Through Three Case Studies, Transportation Research Circular No.E-C262 (2020), 23-36.

[11] N. Ohmori and Y. Dobashi, Research on effectiveness in securing accessibilities by participation of disabled people in public transportation projects, The Foundation for Promoting Personal Mobility and Ecological Transportation (Eco-Mo Foundation), 2018. (in Japanese)

[12] A. Montarzino, B. Robertson, P. Aspinall, A. Ambrecht, C. Findlay, J. Hine, and B. Dhillon, The impact of mobility and public transport on the independence of visually impaired people, Visual Impairment Research 9 (2007), 67-82.

[13] A. Higashiyama, Everyday troubles confronting the individuals with visual impairment, Ritsumeikan Journal of Human Sciences 4 (2002), 99-111. (in Japanese) 